\title{
The Design Patterns for Language Learning and the Assessment on Game-Based Learning
}

\author{
Gridaphat Sriharee
}

\begin{abstract}
Digital game-based learning is the approach to integrate digital games to support learning both inside and outside the classroom. It is promising the way of learning beyond traditional learning where digital learning context is available. The learning game hence requires some qualities that meet both learning outcomes and learner engagement. Thus, the design pattern - a game template for creating the learner game is proposed. Creating such design patterns on the software engineering perspective is presented and their assessment is discussed from the educational perspective. With the proposed design patterns, the design phase ensures that the game design meets the mentioned desires above. Also, it is foreseeable that the design patterns can be reused for developing the learning game for other languages.
\end{abstract}

Index Terms-Design pattern, language learning,
game-based learning.

\section{INTRODUCTION}

In this digital age, mobile devices (e.g., smartphones, tablets) can be accessed from home and schools. Learning hence is not limited to the classroom but is extended to remote learning and self-paced learning. At the same time, parents may need support learning tools to motivate their children on learning in their free time. Digital game-based learning becomes an interesting pedagogy to engage the learner with contents, instructions and teaching techniques that attract the learner learn from play. However, developing the learning game is not easy because it needs to consider many aspects such as content, entertainment, and particularly in the learning outcomes.

In software engineering, a software design pattern is a general, reusable solution to a commonly occurring problem within a given context in software design. It is not a finished design that can be transformed directly into a source or machine code. They are blueprints/templates that can be taken and customized to solve a specific design problem [1]. Design patterns are formalized best practices that the programmer can use to solve common problems when designing an application or system. From the educational perspective, the design patterns are varied according to the purpose of using. For example, the design pattern is introduced as a strategy for representing and disseminating instructional design and learning theory research [2], the

Manuscript received September 16, 2019; revised December 19, 2019 This research was funded by King Mongkut's University of Technology North Bangkok. Contract no. KMUTNB-62-DRIVE-14.

The author is with the Department of Computer and Information Science, Faculty of Applied Science, King Mongkut's University of Technology North Bangkok, 1518 Pracharat I, Wongsawang Subdistrict, Bangsur District, Bangkok, Thailand (e-mail: gridaphat.s@ sci.kmutnb.ac.th). design pattern is the instruction as the procedures for teaching the subjects or topics [3] for network learning.

In this paper, the design pattern is a template that can be used for learning game development. Each design pattern has associated game elements and game attributes. There are still many challenges to specify the patterns or quality of the learning game. Some experts from the educational field and computer science are most related to conducting researched called Co-Creation. The Co-Creation is the approach or activity that combines the educators, stakeholders, and software developments to develop the software game (e.g., [4]). Designing the learning game emerges from the brainstorming. Doing such activity may consume many resources (e.g., time and money) but it is an unavoidable activity to develop the product which all stakeholders require to ensure to have a good production process. Thus, developing the learning game which is a practical approach is still required to meet the desired quality focusing on both software perspective and educational perspective.

From the educational perspective, the educator assessed the learning game to measure how its efficiency to support the learner in learning using pre-test and post-test conditions. The assessment is focused on the learner's engagement and learning outcomes. In contrast to the software engineering perspective, UX/UI becomes the main topic to evaluate the good interface and this can be evaluated by the heuristic approach (e.g., experts, developers) and may involves the user. Thus, assessment is taken before the implementation (i.e., coding) phase. Assessment of the design of the learning games relates to many aspects for example, the learners are different in terms of ages, knowledge, and skills (e.g., reading). Also, a particular learning subject may have particular learning outcomes, teaching techniques, and contents. Therefore, the assessment of the quality of the learning game becomes difficult and this has more difficulty in specifying the standard of the good designs.

This research paper is focused on how to design the patterns for language learning and the Thai language is used as an empirical study that is conducted in the previous work [5]. Although, the design patterns are analyzed, created, and evaluated by implementing on the Thai language learning, however, the proposed methodology can be implemented for other languages. The outcomes of this research are design patterns that are the templates for game development. The assessment of the design patterns is also discussed based on educational purposes.

Section II is a background knowledge and motivation. Section III is the design view of the design patterns considering on software engineering perspective. Section IV presents the design patterns and Section V is their assessment discussed by interactivity with respects to contents, teaching 
technique, and context. Section VI describes the game element and game attributes. Section VII is related work and Section VIII is the conclusion of this paper.

\section{BACKGROUND AND MOTIVATION}

It is possible that technology can substitute or support for a traditional approach. For example, a word processor replacing writing by hand, proofing tools and text-to-speech are used to improve the writing process. Also, technology allows for the creation of new tasks, for example, students combine written text with multimedia, posting the result on a media sharing site. Using ICT support and mobile devices, the learner can learn anywhere and anytime. The promising benefit of using digital-based learning is increasingly individuality which means the activities of the learner can be customized for the individual learners and this supports self-paced learning. However, the applications for learning should be created to support learning such as the creation with particular knowledge or curriculum.

Language learning using application revealed that there are possible to support many learners using a formal learning approach or informal learning approach. There are a number of available applications on the internet, for example, Duolingo and Basuu. These well-known applications focus on communication using vocabulary, translation, and structure for teaching the second language while common vocabularies are adopted. Meanwhile, mother tongue language learning is still required for many countries. The research work of [6] addressed that there is a difference in teaching the first language and second language. The first language acquisition takes place only in a natural context and in the social group where the children get their mother tongue language as the input only but, for second language acquisition can also lead to variations in second language proficiency due to affective factors. The research work of [7] states that the learner learns the first language in an informal and implicit way, in contrast, they learn the second language learning with conscious learning - knowing about language in an explicit and formal linguistic knowledge of the language.

There are many digital games available on the Internet for the Thai language learning. However, most games are providing for learners who learn the Thai language as a second language. The teaching method for this learner is paid attention to memorizing the words and phrases using in daily life. On the other hand, teaching Thai learner needs more understanding of lexical, grammar, and interpretation. Thus, learning materials should implement more lessons. Also, the difficulty of usage of the language should be included in the lesson. Learning the Thai language requires support in reading, writing, listening, and speaking at the same time. The manual for Thai assessment proficiency of the Office of the Basic Education Commission (OBEC) is classified into five disciplines: reading, writing, listening and critical speaking, the principle of natural language and usage in various contexts, and literature. These disciplines are defined for the primary education level 1 to 6 (cf. $7-12$ years old). Education levels 1 to 3 are focused on reading with reading for pronunciation. Education levels 4 to 6 are focused on reading for comprehension and writing of short and long passages as well as prose and poem. In the previous work [5] the summary of needed skills of Thai assessments was classified into 38 learning categories of three primary competencies: reading for pronunciation, reading comprehension, and writing.

This paper proposes the design patterns and how to evaluate the design patterns to ensure that it supports learning according to the game-based learning approach. The obtained design patterns should meet learning outcomes, learner skills, and also maintain the quality with respects to user interface criteria evaluated according to software perspective. Fig. 1 depicts the overview of digital game-based learning using the design patterns. The support system provides the design patterns of the learning game. The design patterns are created by the user interface designer and are used by the software developer. The design patterns are evaluated by educational experts/ teachers as well as the software experts. Thus, the design patterns are given the score that indicates the quality of the game. The evaluated design patterns present the proper user interface design that the software developer may exploit for coding the software game later. Later, the developed games can be downloaded for use inside and outside the classroom.

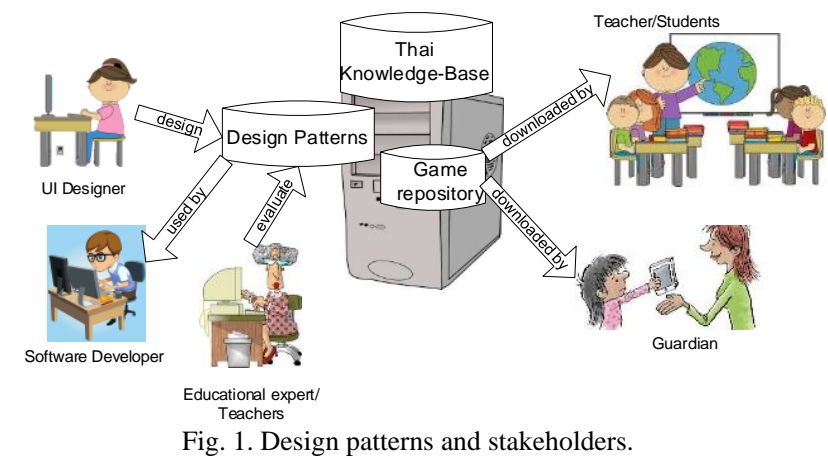

\section{LEARNING GAME DESIGN}

\section{A. Software Engineering Perspective and Game Design}

Learning game is a kind of software, therefore, software development process life cycle and software process in software engineering can be applied for the development. In software engineering, the software process combines software specification, software development, software validation, and software evolution. The two formers software processes involve software requirements, and designing and coding and these processes are focused on particular domains of the software. For example, user requirements state functions that the users/customers need to perform on the system and what they expect to get from the system. Designing the software may implement the models that represent an abstract system of the new system developing. System modeling using some diagrams are used to present the abstract systems. Designing includes the user interface, architectural design and component designs (e.g. programs). Domain modeling can be used for system modeling and it can be represented in terms of several UML diagrams. Software validation focuses on unit testing, system testing, and acceptance testing. After the software is delivered and 
deployed, the software evolution is management for changes (e.g. user requirement changes, bug fixing, technology changes).

Developing a learning game can be conducted by following the software engineering perspective however, the two formers processes are a critical task to create better software. Because these two processes involve stakeholders i.e., teachers, students or learners, parents or guardians, as well as educators who are experts of particular learning topics. The great software learning game hence should be focused on the two processes. In software engineering, design patterns are a means to communicate, identify, and remember solutions to common problems. Each pattern names, explains and evaluates a solution to a common problem. Each design pattern has four essential elements: the pattern name, the problem, the solution, and the consequences [1].

Fig. 2 present the software process for software game design. The process includes software game specifications consisting of software game requirement and educational requirement. Both requirements include functional attributes and non-functional attributes in which these derive learning outcomes (cf. goal). The process of software game design includes the design of game attributes, data model, design patterns, game architecture, game element, and game behavior. The data model means the contents for teaching e.g., questions and answering. The semantic mapping between the data can be provided and this supports automatically retrieval which may support adjusting levels with respects to learner skill. The game attributes are characteristics support in-game (e.g., feedback, board game, story-telling game [8]) whereas, the game element is a (software) component of the game which provides a particular function. For example, rewards, badges, leaderboards, and navigation page.

\section{B. Design Decision}

To design the design pattern, several aspects (see Fig. 3) are considered as follows.

- Game attributes and learning attributes. Each design pattern has required interactivity and therefore, each design pattern may differ from others in both game attributes and learning attribute. The learning attribute are characteristics supports in-game that satisfy learning outcomes.

- Support information in the user interface, for example, media, clue or information, and content. The contents are the question, answers and including audio and video files.

- Teaching techniques are the methods to teach the learner. In this work, language learning techniques are investigated to design the design patterns that are consistent with the teaching technique. One design pattern may support one or more teaching techniques. Therefore, the design pattern can be reused for different purposes of learning.

- Learning topic. One or more design pattern can be used for teaching/learning on the same topics. However, each may support different learning skill.

- Learner skill. Different leaner levels may require a different design pattern for learning the same topic. Thus, the design pattern has one or more related patterns.

Fig. 4 is an architectural design of the learning game. The components of the frontend software are pattern user interface and game elements that perform particular functions. For the backend, the data model is represented in terms of JSON files. The data is the content that displayed in design pattern e.g., questions, and answers, as well as, images, audio, and video files. In this work, the design pattern is implemented by Flutter technology (http://flutter.dev). The design pattern is not only the user interface but it can function to perform some particular tasks (e.g., playing audio, gesture detection, checking answers). Thus interactivity can be examined by using each particular design pattern.

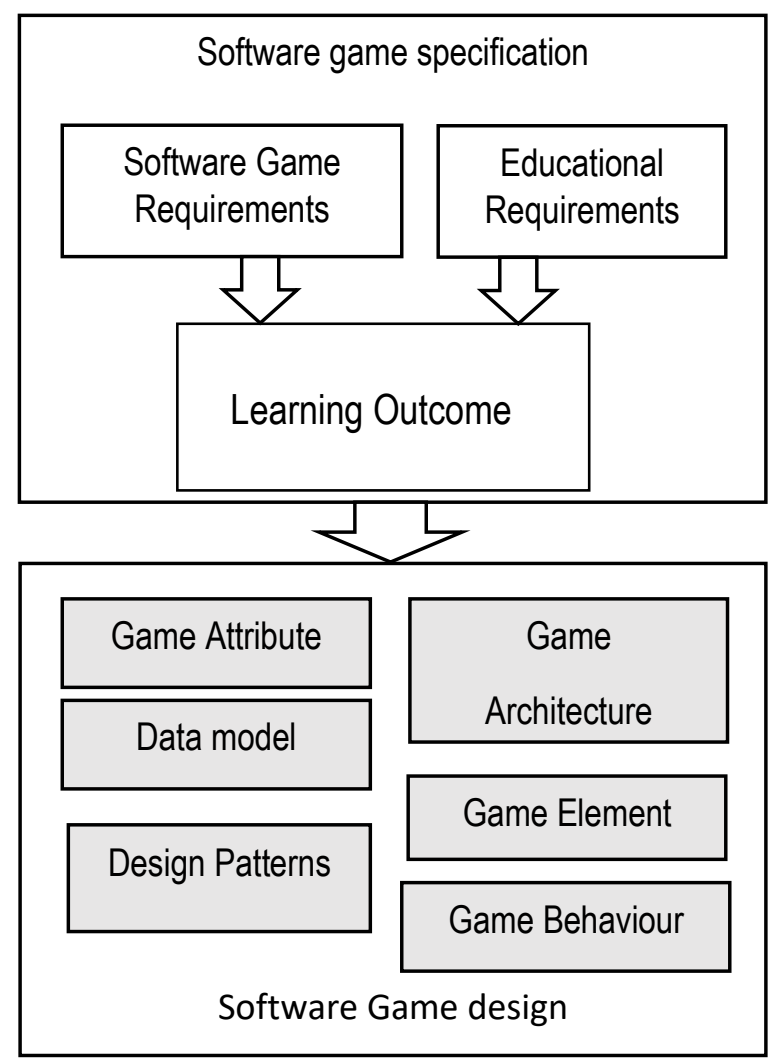

Fig. 2. Software game design.

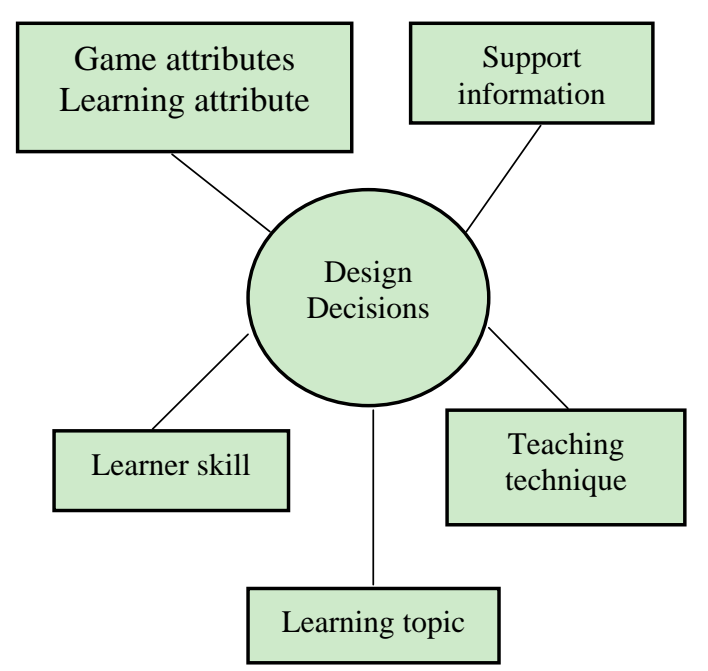

Fig. 3. Design decisions for designing the design pattern. 


\section{DESign PATtern BuILDing}

The manual and design of the learning game for teaching the Thai language are investigated. Also, the applications available on the App Store and iOS store. Duolingo (http://www.duolingo.com) is explored as it is a well-known application for learning a language. The design of the user interface that has usability with good performance. However, there are not many styles of the user interface provided in the application. Thus, the design of the learning game is created by focusing on ease of use, clear and simple as the main characteristics. In the prior step, there are 17 design patterns created in which these are categorized into 11 design pattern in which some patterns may have more than one related patterns. Some of the design patterns are shown in Fig. 5 (a) (f). The patterns are Grid style (a,b), Scrabble style (c), Quiz style (d), Ordering style (e), and Tone styles (f). For teaching, the pronunciation of the tone in the language, the design is quite complicated as well as teaching technique is quite difficult. One design pattern can be designed into one or more patterns for example, the Grid style for teaching vowel (a) is extended into the Grid style for teaching word combination (b). Gesture detection such as tapping and drag and drop are the main elements for interactivity. Each design pattern represents different gameplay. For example, the design pattern Scrabble style (b) is used for learning to extract words from the mentioned word. In playing, the user is required to drag the letters of each word.

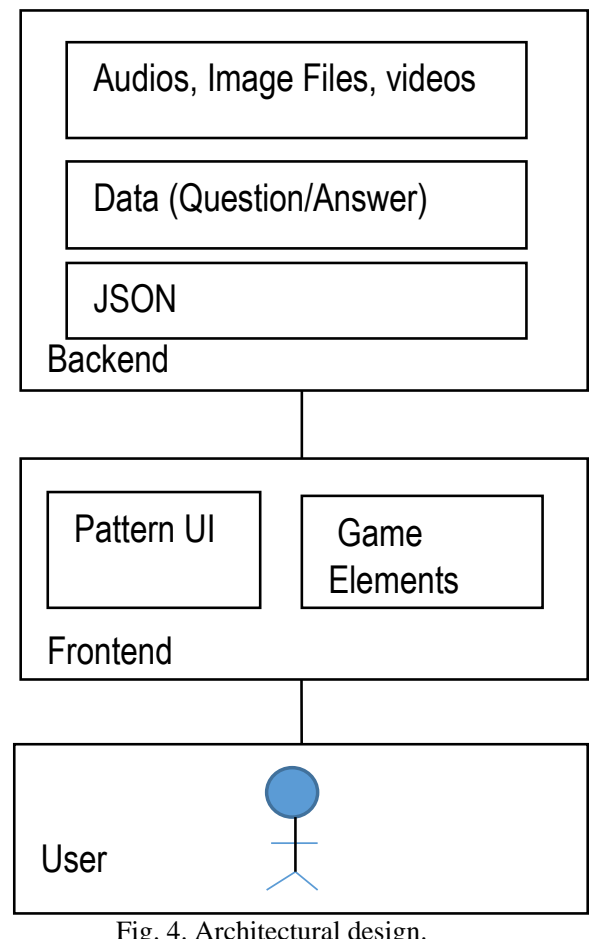

\section{A. Pattern and Learning Skill}

Fig. 6 (a) and (b) depict user interfaces for the same question, however, these UIs practice different learning skill. The question asks about vocabulary for representing the verb of eating the food of the monk and normal people which the answers are 'ฉัน' and 'กิน'. Using a Fill-in design pattern, practicing skills to distinguish the words are learned in contrast, using the Quiz design pattern has more difficulty and distinguishing is also difficult for the learners because of many options. Thus, the Fill-in design pattern is seemed appropriate for learning more than the Quiz design pattern. In case, the game provides learning and testing mode, the second may be more challenge for the high-level learner. The related design pattern of the Fill-in design pattern provides sorting function, for example, Fig. 6 (c) depicts the sorting letters for the word which has the meaning as a hat. This pattern supports writing skill and learning word meaning. The users can move any letter until all letters are in the correct positions. Thus, each pattern supports different learning attribute (i.e., learning skill), for example, the Quiz design pattern focuses on comprehension than writing skill.

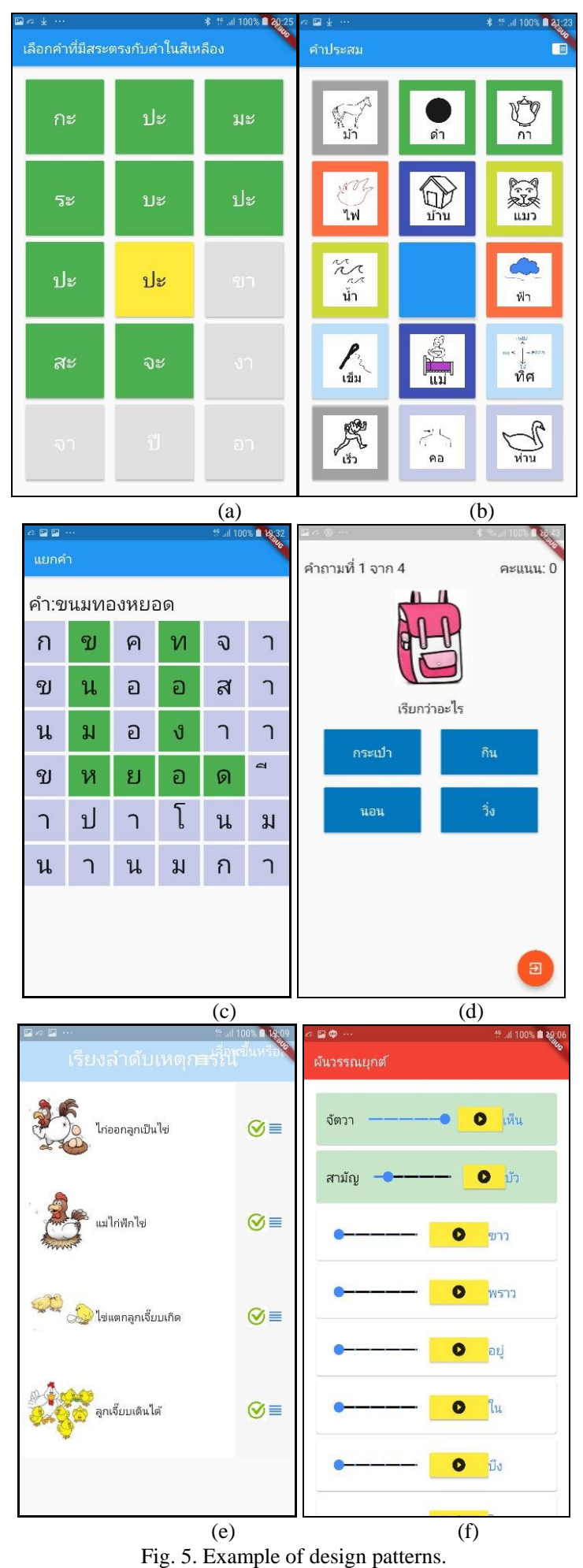

Fig. 5. Example of design patterns. 


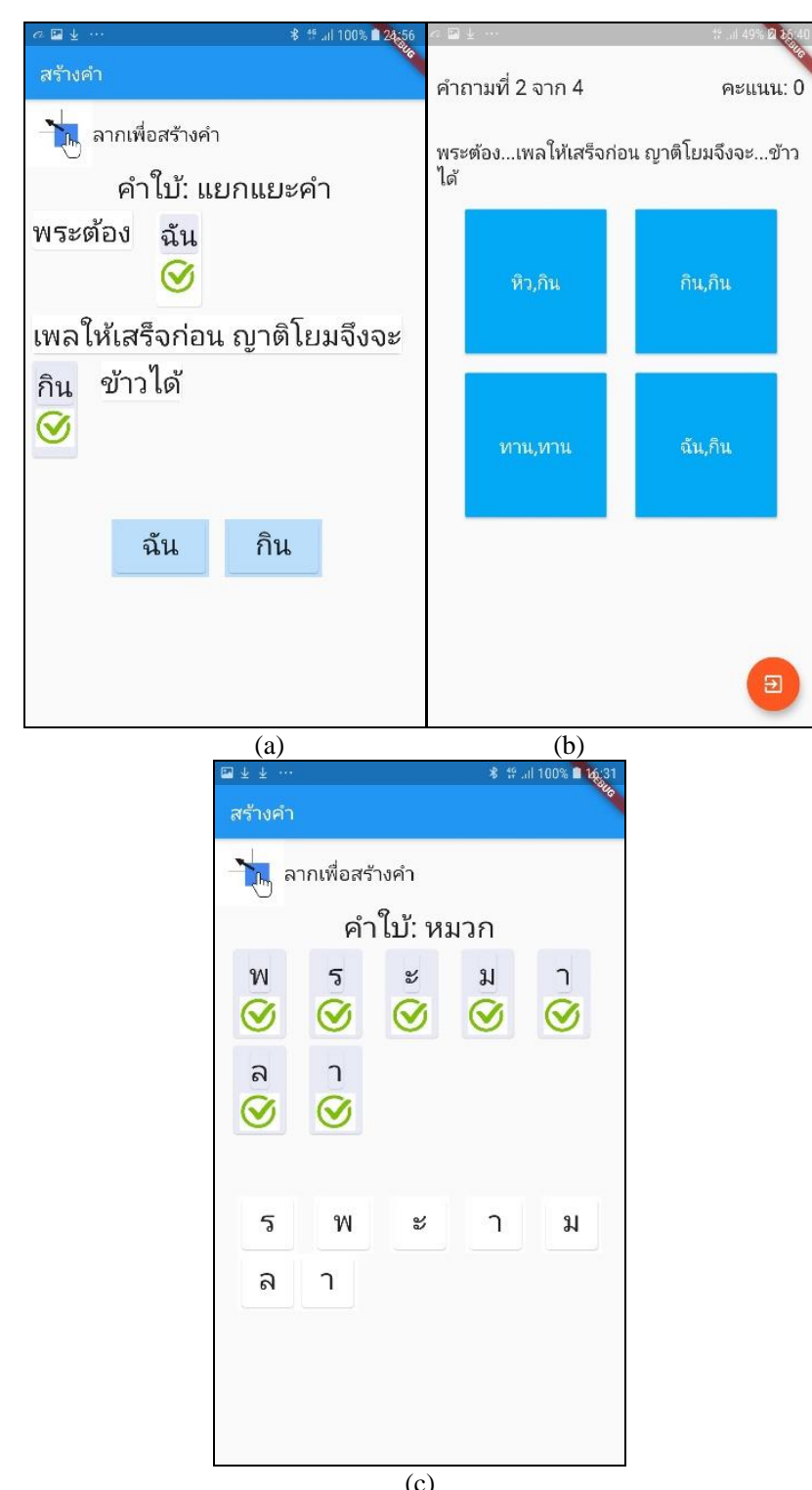

Fig. 6. (a) Fill-in design pattern, (b) Quiz design pattern (c) Fill-in design pattern.

\section{B. Pattern and Learner Level}

User interface design for children is a challenge topic. [9] proposed factors for user interface design into emotional support, language support, cognitive support, memory support, and interaction support. [10] conducted the research to investigate the user interface of the children 3-12 years old. Their report said many of the users under 6 had never used a computer before, but they were comfortable browsing apps, games, and websites using tablet and mobile devices. Some realized studies that are different from adults are, for example: they need instant gratification, reading depending on levels but most of them do not read, font size are 14, 12 point for the young and older children respectively, scrolling should be avoided, animation and sound are required, and slow typist and poor mouse control. Also, they recommended that the user interface of the children may be varied according to the different ages. The design to distinguish between young (3-5 years old), mid-range (6-8 years old), and older (9-12 years old) children can be provided because the children are aware of the content of the younger children. Thus, the design pattern may have one or more related patterns. Because the Thai learning educates the students in two education levels: primary (Prathomsuksa 1 3 (age 7-9 years old) and secondary education level (Prathomsuksa $4-6$ (age 10-12 years old) and hence the design patterns are provided for the two learner levels. Fig. 7 depicts an example of a design pattern - matching style (a), to match the word of nouns with the objects in the kitchen for the primary education level whereas, the second style (b) is provided for the secondary education level (Prathomsuksa 4 6).

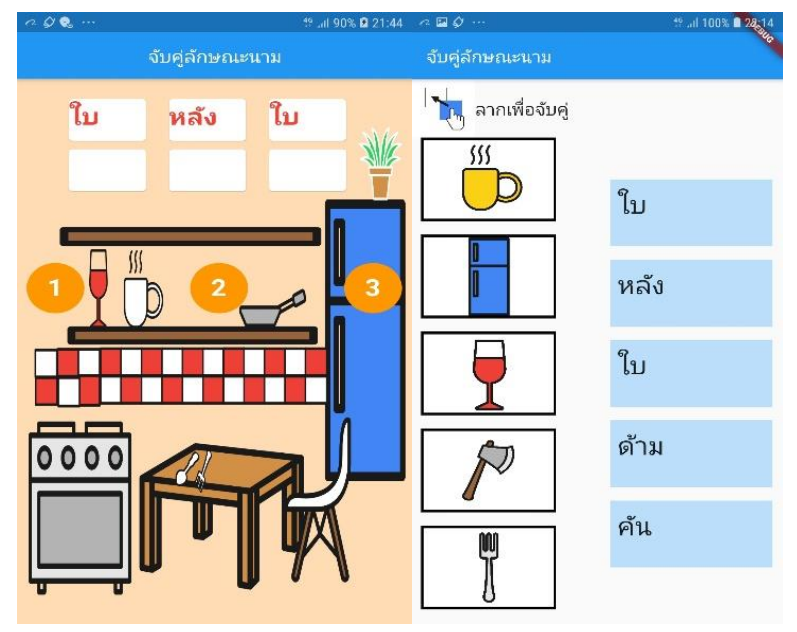

(a)

(b)

Fig. 7. Design patterns for (a) the primary education level and (b) the secondary education level.

\section{Design PATtern Assessment}

To evaluate the educational game, [11] suggested some aspects for the evaluation such as usability, learnability, playability, and accessibility. The approach to evaluate can be heuristics, user-centric, analysis, and guidelines. The automated tool can support the evaluation. The heuristic approach requires experts e.g., educational expert and UX/UI experts and user-centric may involve teachers and students. Measuring pre-test and post-test of the student can be one of the techniques to evaluate learning performance. In the software engineering perspective, evaluation can be considered in the design phase or before the coding phase. Evaluation by the users can be conducted to evaluate user acceptance regarding the non-functional attributes (e.g., usability, learning performance).

There are no base-line documents or standard for user interface design for the educational game and therefore, the practical approach to evaluate the design pattern in this paper is based on 'fit to purpose' principle. For example: do the design patterns align with the teaching technique and learning outcome? and do the design patterns provide the user interface that supports the learner level and skill?. Thus, the design pattern follows the heuristic approach but uses the perspective of assessment in the works of literature for this evaluation. Also, the assessment is evaluated on the bottom-to-top view which means from the concrete design to perceptions. The assessment attributes were analyzed from the internal attributes (e.g., game attribute, user interface components) and to the learning attributes that represent perceptions on learning. In this work, the assessment is hence 
focused on interactivity, teaching technique and context of use.

\section{A. Interactivity}

Learning design can be analyzed from the technique that the teachers or educators apply for teaching. It should have complied with the scientific research methodologies. For human-computer interaction, the interactivity is evaluated. [12] described the term interactivity as the functions and/or operations made available to the learner to enable them to work with content material presented in a computer-based environment. He also suggested the interactive constructs identified by learners, content, pedagogy, and context. In this paper, the interactivity is defined according to the suggested concepts and focus on the learners, content, and context. With the suggestion, pedagogy focused on the learning activity the users interacting with the system such as navigating, testing, and self-pacing. In this work, teaching techniques can be evaluated as the pedagogy aspect. Context aspects associate to the environment and the system and this is limited for the evaluation of the design patterns.

Three important aspects are defined for the design pattern assessment with detail as follows.

1) Content. This aspect includes the assessment to ensure that the content supports the learning aspect and the required UI aspect with detail as follows.

- UI aspects. The learning is computer-learner interaction with support interfaces and information (e.g., picture, audio, video).

- Learning aspects. The design patterns support learning the alphabet, vowel, sentence, passage (short and long passage), as well as support learning with respects to meaning and learning outcome.

2) Teaching technique. This aspect focus on how the design pattern supports teaching technique.

3) Context. This considers interactivity between the system, context, and users. The proposed game-based learning supports mobile learning.

Table I is an example of the aspects and criteria for analysis of the design pattern with respects to the content. Learning aspects also evaluated according to the cognitive strategy defined in the Bloom theory [13]. Consistency of the questions and Bloom's cognitive level is shown in Table II. Because the design pattern does not focus on the pattern that has the passage, therefore evaluation and synthesis level are not analyzed.

\section{B. Teaching Technique}

Teaching techniques may vary according to language and learners. However, some common techniques can be introduced to any language. [14] proposed a language learning strategy. The language learning strategy comprises of memory, cognitive and comprehension strategy.

For the Thai language learning, [15] published the manual of teaching activity implementing game for teaching the Thai language for the student. Her book has been published 10 times since 2007. The recent publishing proposed 132 learning activities.

Table III presents the results of the assessment according to the example of 30 teaching techniques analyzed from the manual of [15] and the proposed design patterns. The content is the representation of information that teaches the learner to learn and this can be alphabets (A), vowel (V), word (W), passage $(\mathrm{P})$. The content may be represented by associating it to the linguistics (L) (e.g., noun, verb, or grammar), and meaning (M). Because one teaching technique may rely on previous required skill. For example, No. 6 teaches combining word from one or more single words haa previous required skill (column RS) regarding linguistics and meaning before. The column LO represents learning outcome that associates to (I) reading for pronunciation and (II) reading for comprehension categorized in the previous work [5]. One teaching technique may correspond to one design pattern and each technique supports particular learning outcome.

TABLE I: ASPECTS AND CRITERIA FOR THE CONTENT ASSESSMENT

\begin{tabular}{|c|c|}
\hline 1. Learning aspect & Criteria \\
\hline 1.1 Understanding & $\begin{array}{l}\text { - Present question clearly } \\
\text { - Enable learner elaboration of epitomes [12] }\end{array}$ \\
\hline 1.2 Essential & - Ensure interactions implemented [12] \\
\hline 1.3 Engagement & $\begin{array}{l}\text { - Integrate meaningful engagement through } \\
\text { access to different content representation [12] } \\
\text { - Enable the means to control displayed media } \\
\text { elements [12] }\end{array}$ \\
\hline 1.4 Minimalist & - Include only necessary content \\
\hline 1.5 Skill-based & $\begin{array}{l}\text { - Support skills defined in the Bloom taxonomy. } \\
\text { See Table II. }\end{array}$ \\
\hline 1.6 Learning outcome & $\begin{array}{l}\text { - Support learning category - reading } \\
\text { pronunciation, reading comprehension, and } \\
\text { writing, defined in the previous work [5]. }\end{array}$ \\
\hline 2. Required UI aspect & Criteria \\
\hline $\begin{array}{l}\text { 2.1Question answering } \\
\text { format }\end{array}$ & $\begin{array}{c}\text { - Each design pattern adopt cyclic question, } \\
\text { answer, and feedback [12]. }\end{array}$ \\
\hline $\begin{array}{l}\text { 2.2 Cognitive feedback } \\
\text { and assistance }\end{array}$ & $\begin{array}{c}\text { - Each design pattern provide sufficient feedback } \\
\text { e.g., sound effects, visual feedback, textual } \\
\text { corrections } \\
\text { - Clue or help, noticing support, } \\
\text { and memorisation aid [12]. }\end{array}$ \\
\hline 2.3 Learning skill & $\begin{array}{l}\text { - A design pattern associates to particular } \\
\text { learning skill. See section IV (a). }\end{array}$ \\
\hline 2.4 Learner level & $\begin{array}{l}\text { - A design pattern associates to particular leaner } \\
\text { level. See section IV (b). }\end{array}$ \\
\hline
\end{tabular}

TABLE II: QUESTIONS AND COGNITIVE LEARNING STRATEGY

\begin{tabular}{|c|c|}
\hline $\begin{array}{c}\text { Cognitive } \\
\text { learning } \\
\text { Strategy }\end{array}$ & Example of questions \\
\hline Remembering & $\begin{array}{c}\text { - Which word is noun? } \\
\text { Comprehension }\end{array}$ \\
\hline Applying & $\begin{array}{c}\text { - What is synonym of the word ....? } \\
\text { - Rephrase the sentence ... }\end{array}$ \\
\hline Analyzing & $\begin{array}{c}\text { - Cuess the word that relates to the word .... } \\
\text { - Plan your activities using the words that } \\
\text { represents ordering events. }\end{array}$ \\
\hline & $\begin{array}{c}\text { - Categorise the words that are in the same group. } \\
\text { - Which word is different from the others? }\end{array}$ \\
\hline
\end{tabular}

Additional assessment can be evaluated by the users such as teachers and learners. Some of the questions that can be investigated are as follows.

Q1: Does the design patterns are suitable for learner skills? Q2: Does the design pattern enhances learner learning? 
Q3: Does the design pattern aligns with the teaching technique?

Q4: Evaluation of design perspective: difficult, moderate, and easy.

For the question Q1 and Q3, the proposed method of analysis presented in this paper reveals the answer. Flexible data retrieval can be an important issue that ensures that the learner achieves a particular skill level. Answering the question Q2 and Q4 can be evaluated by pre-test and post-test when the game is applied for the learner in learning.

\section{Context}

The design pattern is aimed to be used in the mobile environment. Thus, assessment according to the mobile context between the proposed system and context, and the users and context are analyzed. [16] proposed some metrics of assessment such as visibility operation enjoyment, ease, efficiency, and enjoyment.

The proposed framework and architectural design (Section III (B)) require the internet to support the framework. Also, images, audios, media files influence the size and storage of the software game and this is important for software validation to ensure that the developed game support learning in the learner's context efficiently.

\section{Game Element and Game Attribute}

[8] proposed the game attributes for learning, for example, assessment, achievement, content, meaning, outcomes, competition, rules, context, problem-solving. They focus on the characteristics of the games which are perceived by the users. Here, the game attributes are functional attributes (e.g. feedback, achievement) and non-functional attributes (e.g. problem-solving, competition). The game element is part/components of a game. A game element may represent the game attribute. Each design pattern may consist of one or more game elements. Fig. 8 shows an example of some pages that can be seen as the game elements. For playing the game ordering actions of the actor in the video, created by the design pattern, there may have one or more pages: game list (a), video player page (c), and the learning activity page (c). Adding more game elements means adding game attributes. However, some design patterns have a specific attribute for example, the Grid design pattern can be applied to be the board game by adding a challenge into the game. Challenge can be defined in many characteristics such as performing a task within the given time, and the correction of the answers. The game element such as bonus and badge can support the complete functionality of a game. Fig. 8 (d) represents the well-known pattern of the OX board game which requires human-computer interaction. This type of game can be seen as a game that is embedded by learning.

TABLE III: TEACHING TECHNIQUE ASSESSMENT

\begin{tabular}{|r|l|l|l|l|}
\hline N. & Teaching technique & Content & RS & LO \\
\hline I & Alphabets pronunciation & A & & I \\
\hline 2 & Vowel pronunciation & V & & I \\
\hline 3 & Sorting alphabets & A,L & & II \\
\hline 4 & Learn vocabulary and its meaning & W,P,M & & II \\
\hline & & W,P,L, & & \\
5 & Learn word linguistic & M & & II \\
\hline 6 & Combining word & W,P,M & L,M & II \\
\hline
\end{tabular}

\begin{tabular}{|r|l|l|l|l|}
\hline 7 & Create word from alphabets and vowels & $\begin{array}{l}\text { A,V,W, } \\
\text { P,M }\end{array}$ & & II \\
\hline 8 & Distinguish vowel (Short,long sound) & V,W,L & & II \\
\hline 9 & $\begin{array}{l}\text { Distinguish words(e.g., noun, verb, } \\
\text { adjectives,...) }\end{array}$ & W,L & & II \\
\hline I0 & Fill in the blank & $\begin{array}{l}\text { A,V,W, } \\
\text { P,L,M }\end{array}$ & L,M & II \\
\hline II & $\begin{array}{l}\text { Create new word from previous known } \\
\text { words }\end{array}$ & W,M & L.M & II \\
\hline I2 & Fill in the blank & W,P,M & L,M & II \\
\hline I3 & Antonym, synonym & W,P & M & I \\
\hline I4 & Using repeatedly word & W & & I \\
\hline I5 & Using more words & W,M & & II \\
\hline I6 & Create sentence from words & W,L & M & II \\
\hline I7 & Matching word types, word association & W,L,M & M & II \\
\hline I8 & $\begin{array}{l}\text { Ordering the events from picture, } \\
\text { passage }\end{array}$ & P & & II \\
\hline I9 & $\begin{array}{l}\text { Pronunciation of word with many } \\
\text { syllables }\end{array}$ & W,M & M & II \\
\hline 20 & Silent letter & W,L & & I \\
\hline 2 I & Categorizing words & W,L,M & & I \\
\hline 22 & One word has many meaning & W,M & M & II \\
\hline 23 & Matching alphabets, vowels, or words & A,V,W,M & M & II \\
\hline 24 & Drawing to learn alphabet & A,L & & I \\
\hline 25 & Drawing to learn word & W,L,M & & I \\
\hline 26 & Tone mark training & W & & I \\
\hline 27 & Sorting tone mark & W & & I \\
\hline 28 & Word and reading & W,L & & I \\
\hline 29 & $\begin{array}{l}\text { Create new word from previous known } \\
\text { words }\end{array}$ & W,L,M & L,M & II \\
\hline 30 & Count syllable, reading syllable & W & & I \\
\hline & & & & \\
\hline
\end{tabular}

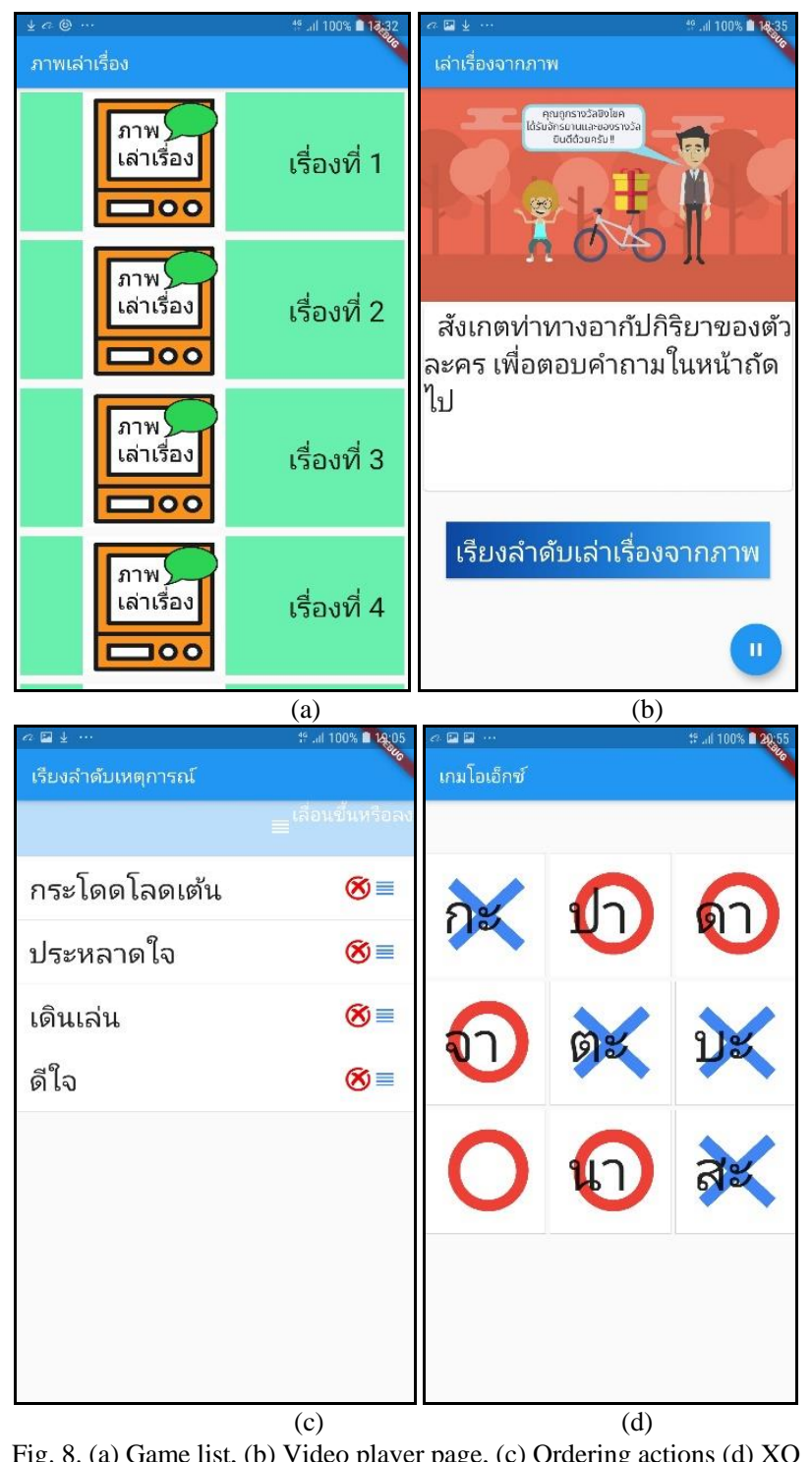

Fig. 8. (a) Game list, (b) Video player page, (c) Ordering actions (d) XO game. 


\section{RELATED WORK}

For the software engineering perspective, the design patterns are the artifacts for software development. They can be represented regarding the model of code or as the template for creating the software for the particular system. Applying design patterns with educational learning is addressed in some works as follows. [17] proposed the design pattern with respects to the software engineering perspective for the serious game. Their pattern is determined after investigating twenty serious games. Their design patterns concern both the learning aspect and the fun aspect. [2] specified the design pattern for network learning. The design pattern is the pattern for the teacher in collaboration during network learning.

Conducting the language learning game may rely on one particular design pattern. For example, [18] proposed two learning games to learn the lexicon and morphology of English, French and Italian. Learning language can have more fun by enhancing a visualization or animation during teaching, for example, [19] proposed an interactive system using a virtual language teacher for teaching speech communication.

The design patterns can be derived from the model for example, by the CTT model. Some research works proposed the game design from the CTT model are as follows. [20] use CTT model for a game scenario modeling. They show how the model can be used to analyze and structure pedagogical content about the procedures and to support and monitor procedure execution in the game. [21] proposed the use of the CTT model to create the abstract user interface of a business operation domain. [22] proposed the design of mobile application for the language learning. They focused on localized design which means designing the application from the real context of learning.

In the previous work [5], the CTT model is adopted for game design and the abstract user interface derives from the task model. However, the components of the software can be seen as a complex or a simple component and thus, mapping a task to the component can be represented by different layouts and components. This paper hence proposes the design from the top-to-bottom perspective view which is more abstract but the design still supports the task activity. By doing so, it is flexible for management and aligns with the software engineering principle from software specification to the software design phase.

\section{CONCLUSION AND FUTURE WORK}

This paper proposed the methodology to design the design patterns and their assessment are discussed from both software perspective and educational perspective. The design pattern can be reused as the components of the developing game. Each design pattern has its usage information such as learning skill, learner level, and support teaching techniques. This information is the guideline for the developer to create the learning game. Although the Thai language learning is investigated as a case study however, the proposed design patterns can be adopted for implementing learning in other languages. By separating the data model from the design pattern, it means that flexible retrieval of the data which is the content of the game can be specified further. In doing so, adapting the content to meet the leaner skills can be implemented and this will be developed for future work.

The proposed methodology of assessment embraces both software engineering perspective and educational perspective together. It is obvious that developing the learning game has specific characteristics in which the content is the most critical factor whereas, entertainment in-game is still required to create the engagement. Using game-based learning can be the approach to motivate them to learn by self-paced. Also, teachers and parents can support their children to learn by using the digital game rather than using a paper-based homework and this enhances the cognitive skill. However, collaboration, and social activity between the leaners, teachers, and parents, are still important to motivate the intrinsic motivation of the learner.

\section{CONFLICT OF INTEREST}

The author declares no conflict of interest.

\section{AUTHOR CONTRIBUTIONS}

The author conducted the research and wrote the research paper. The author had approved the final version.

\section{REFERENCES}

[1] E. Gamma, R. Helm, R. Johnson, J. Vlissides, and G. Booch, Design Patterns: Elements of Reusable Object-Oriented Software 1st Edition, Addison-Wesley Professional Computing Series, 1995.

[2] S. Rohse and T. Anderson, "Design patterns for complex learning," Journal of Learning Design: Designing for Effective Learning, vol. 1, no. 3, pp. 81-89, 2006.

[3] P. Goodyear, "Educational design and networked learning: Patterns, pattern languages and design practice," Australasian Journal of Educational Technology, vol. 21, no. 1, pp. 82-101, 2005.

[4] H. Tobar-Muñoz, S. Baldiris, and R. Fabregat, "Co design of augmented reality game-based learning games with teachers using co-CreaARGBL method," in Proc. 2016 IEEE 16th International Conference on Advanced Learning Technologies (ICALT), pp. 120-122, 2016.

[5] G. Sriharee, "Toward design pattern of digital game-based learning for Thai language learning," in Proc. European Conference on Game-Based Learning, Sophia-Antipolis, France, pp. 626-633, October 5-6, 2018.

[6] H. Ipek, "Comparing and contrasting first and second language acquisition: Implications for language teachers," Journal of English Teaching Language, vol. 2, no. 2, pp. 155-163, June, 2009,

[7] S. Krashen, "Theory versus practice in language training," Innovative Approaches to Language Teaching, Rowley, MA: Newburry House Publishers, pp. 15-24, 1982.

[8] Z. Alaswad and L. Nadolny, "Designing for game-based learning: The effective integration of technology to support learning," Journal of Educational Technology Systems, pp. 389-402, July 17, 2015.

[9] T. Gossen, M. Nitsche, and A. Nürnberger, "Search user interface design for children: challenges and solutions," in Proc. the 2nd European Workshop on Human-Computer Interaction and Information Retrieval, pp. 59-62, August 24-25, 2012.

[10] K. Sherwin and J. Nielson. (2019). Children's UX: Usability issues in designing for young people. [Online]. Available: https://www.nngroup.com/articles/childrens-websites-usability-issues/

[11] J. N. Marciano, L. C. D. Miranda, and E. E. C. D. Miranda, "Evaluating multiple aspects of educational computer games: Literature review and case study," International Journal of Computer Games Technology, 2014.

[12] R. Sims, “An interactive conundrum: Constructs of interactivity and learning theory," Australian Journal of Education Technology, vol. 16, no. 1, 2000, pp. 45-57.

[13] B. S. Bloom, Taxonomy of Educational Objectives, Handbook I: The Cognitive Domain, New York: David McKay Co Inc, 1956.

[14] R. Oxford, Language Learning Strategies, New York, 1990. 
[15] A.

Cheewapan,

พัฒนาทักษะภาษา พัฒนาความคิดด้วยกิจกรรมการเล่นประกอบการสอนภาษาไทย, ISBN 9789740326076, 2017.

[16] N. A. Ismail, F. Ahmad, N. A. Kamaruddin, and R. Ibrahim, "Review on Usability Issues in Mobile Applications," IOSR Journal of Mobile Computing \& Application (IOSR-JMCA), vol. 3, issue 3, pp. 47-52, May-Jun. 2016.

[17] B. Huynh-Kim-Bang, J. Wisdom, and J. M. Labat, "Design patterns in serious games: A blue print for combining fun and learning," Project SE-SG, pp. 1-18, 2010.

[18] M. Roccetti, P. Salomoni, M. Loiseau, M. Masperi, V. Zampa, A. Ceccherelli, and A. Valva, "On the design of a word game to enhance Italian language learning," in Proc. 2016 International Conference on Computing, Networking and Communications (ICNC), pp. 1-5, 2016.

[19] P. Wik and A. Hjalmarsson, "Embodied conversational agents in computer assisted language learning," Speech Communication, vol. 51, no. 10, pp. 1024-1037, 2009.

[20] A. C. Vidani and Chittaro, "Using a task modeling formalism in the design of serious games for emergency medical procedures," in Proc. the International Conference on Games and Virtual Worlds for Serious, in 2009 Conference in Games and Virtual Worlds for Serious Applications, pp. 95-102, March, 2009.
[21] M. Atanasova and A. Malinova, "Transforming concur task trees model into an abstract user interface," in Proc. CBU International Conference, pp. 1036-1041, September 2017.

[22] M. Kam, D. Ramachandran, V. Devanathan, A. Tewari, and J. Canny, "Localized iterative design for language learning in underdeveloped regions: the PACE framework," in Proc. the SIGCHI Conference on Human Factors in Computing Systems, pp. 1097-1106, April, 2007.

Copyright $\odot 2020$ by the authors. This is an open access article distributed under the Creative Commons Attribution License which permits unrestricted use, distribution, and reproduction in any medium, provided the original work is properly cited (CC BY 4.0).

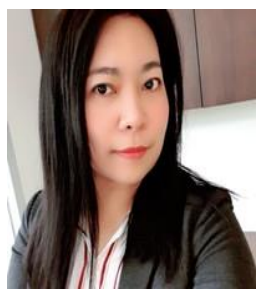

Gridaphat Sriharee received her Ph.D. in computer engineering from Chulalongkorn University, Thailand. She is an associate professor and currently teaching at the Department of Computer and Information Science, King Mongkut's University of Technology North Bangkok, Bangkok, Thailand. Her interests include software engineering, learning game, semantic computing, and data science. 